\title{
Stage III Nasal Cavity Cancer AJCC v6 and v7
}

National Cancer Institute

\section{Source}

National Cancer Institute. Stage III Nasal Cavity Cancer A/CC v6 and v7. NCI Thesaurus. Code C6011.

Stage III includes: (T3, N0, M0); (T1, N1, M0); (T2, N1, M0); (T3, N1, M0). T3: Tumor invading the medial wall or floor of the orbit, maxillary sinus, palate, or cribriform plate. T1: T umor restricted to any one subsite, with or without bony invasion. T2: Tumor invading two subsites in a single region or extending to involve an adjacent region within the nasoethmoidal complex, with or without bony invasion. N0: No regional lymph node metastasis. N1: Metastasis in a single ipsilateral lymph node, $3 \mathrm{~cm}$ or less in greatest dimension. M0: No distant metastasis. (AJCC 6th and 7th eds.) 